\title{
Peningkatan Pengetahuan Lansia tentang Hipertensi Emergensi melalui Pendidikan Kesehatan
}

\author{
Isnaini Rahmawati ${ }^{{ }^{*}}$, Dewi Suryandari ${ }^{2}$, Noerma Shovie Rizqiea ${ }^{3}$ \\ ${ }_{1,2,3}^{1}$ Universitas Kusuma Husada Surakarta \\ *Email: isnaini.rahmawati88@gmail.com
}

\begin{abstract}
Abstrack
Background: Hypertension is a disease that not many people know before examining their blood pressure, so it is called with silent disease. Increased self-knowledge of this disease becomes the basis for individuals to make the decisions for the treatment. With good knowledge, we hope that the effects and complications of hypertension can be prevented. For this reason, health education is needed regarding hypertensive emergencies in elderly, because the elderly include in one of the groups at risk for hypertension, this is due to a decrease in physiology from increasing age. The purpose is to increase the elderly's knowledge about hypertensive emergencies, so as to prevent the occurrence of these events. Methods: Health education through counseling during posyandu activities was used in this activity, the knowledge was measure using questionnaire. Results: After this activity, the elderly understood about hypertensive emergencies and also knew what steps should be taken if such an event occurs. Conclusion: The increasing about knowledge in definition was $82,1 \%$, the sign and symptom was 52\%, and the treatment was $45 \%$.
\end{abstract}

Keywords: elderly, health education, hypertensive emergencies

\section{PENDAHULUAN}

Hipertensi ditandai dengan meningkatnya tekanan pada aliran darah yang ada pada tubuh manusia, sehingga meningkatkan tekanan didalam pembuluh darah. Joint National Commitee VII (2014) menyebutkan bahwa usia lebih dari sama dengan 18 tahun dengan tekanan darah sistolik $\geq 140 \mathrm{mmHg}$ dan tekanan darah diastolik $\geq 90$ $\mathrm{mmHg}$ merupakan kategori seseorang dikatakan hipertensi. Penyakit hipertensi ini dapat dijumpai pada usia muda dan juga usia lanjut karena proses degeneratif (Kemenkes, 2014). Penyakit ini juga sering disebut sebagai silent killer, karena pada beberapa kasus tanda dan gejala tidak muncul secara nyata (Kowalski, 2010).

Beberapa tanda dan gejala yang dapat muncul pada penderita hipertensi berbeda-beda, antara lain pusing, nyeri di tengkuk leher, muncul vertigo, lelah, blurd (pandangan kabur), takikardi dan telinga yang berdenging (Kemenkes, 2014). Beberapa penyebab terjadinya hipertensi di era modern adalah perubahan gaya hidup, antara lain konsumsi fastfood, kurangnya aktivitas, kurangnya kegiatan yang bersifat olahraga. Penyakit ini dapat terjadi pada negara maju maupun berkembang (Martha, 2012).

World Health Organization (WHO) (2013) menyebutkan bahwa pada tahun 2025, prevalensi penyakit hipertensi ini diperkirakan baik hingga 29\%. Sejumlah 74,5 juta jiwa diprediksi naik pada usia diatas 20 tahun, dan tidak terdeteksi faktor pencetusnya (American Health Association, 2013). Prevalensi penderita hipertensi di dunia yang meninggal sejumlah 8 juta jiwa setiap tahunnya dikarenakan tidak diketahui sejak dini penyebabnya, dan 1,5 juta diantaranya terjadi di Asia Tenggara (Kemenkes, 2014). 
Indonesia merupakan negara yang angka kejadian hipertensinya tinggi. Hasil Riset Kesehatan Dasar (2018) menyebutkan bahwa prevalensi penyakit hipertensi mengalami peningkatan $34.1 \%$ lebih tinggi $2 \%$ dibandingkan dengan hasil Survey Indikator Kesehatan Nasional (2016) yaitu 32,4\%. Dan prevalensi ini diperkirtakan meningkat dari tahun ke tahun, salah satunya di Jawa Tengah. Berdasarkan hasil Survey tahun 2016 di Jawa Tengah, salah satu Penyakit Tidak Menular (PTM) yang kejadiannya tergolong tinggi adalah hipertensi, yaitu sebesar 473.603. Kabupaten Sukoharjo merupakan urutan ke 10 pada kasus kejadian hipertensi terbanyak di Jawa Tengah, yaitu 13.245 kasus (Dinkes Jateng, 2016)

Pengendalian hipertensi di Jawa Tengah perlu dilakukan untuk mencegah komplikasi, mengingat kejadian ini selalu mengalami peningkatan. Komplikasi yang paling parah yaitu kematian, kurang lebih 9,4 kasus di dunia setiap tahunnya, 45\% kematian karena penyakit jantung, dan $51 \%$ karena penyakit stroke. Kemenkes RI (2014) memprediksikan kematian hingga 23,3 juta pada tahun 2030. Pengetahuan yang kurang, akan mempengaruhi penderita hipertensi untuk bisa mengatasi recurrent atau melakukan tindakan-tindakan pencegahan agar tidak terjadi komplikasi. Pendidikan merupakan salah satu indikator untuk mengukur pengetahuan, sehingga pendidikan merupakan salah satu faktor yang dapat mempengaruhi lansia memahami tentang penyakitnya. Dengan adanya pengetahuan yang kurang, maka resiko untuk terjadi kekambuhan meningkat dan dapat meningkatkan pula resiko untuk terjadinya peningkatan tekanan darah yang mendadak (hipertensi emergensi) yang berujung ke kematian. Berdasarkan penjelasan mengenai penyakit tersebut diatas, maka penulis tertarik untuk melakukan pendidikan kesehatan kepada lansia tentang hipertensi emergensi.Tujuan dari kegiatan ini adalah meningkatnya pengetahuan lansia tentang hipertensi emergensi, sehingga dapat mencegah terjadinya kejadian tersebut

\section{TINJAUAN PUSTAKA}

\subsection{Hipertensi Emergensi}

Hipertensi emergensi didefinisikan sebagai peningkatan tekanan darah (TD) yang berat $(>180 / 120 \mathrm{~mm} \mathrm{Hg})$ dan disertai bukti kerusakan baru atau perburukan kerusakan organ target (target organ damage=TOD) (Whelthon et all, 2017). Organ Target yang dimaksud adalah jantung, otak dan ginjal.Tindakan yang harus dilakukan untuk mengatasi hipertensi emergensi adalah menurunkan tekanan darah dengan cepat, tindakan pemberian anti-hipertensi (parenteral) dosis tertentu dapat dilakukan untuk mengatasinya. Bila organ target tidak terkena, proses penurunan tekanan darah pada hipertensi emergensi dapat diturunkan dalam 24-48 jam.

Tanda dan gejala pada hipertensi emergensi adalah peningkatan tekanan darah yang mendadak untuk tekanan darah sistolik > $180 \mathrm{mmHg}$ atau tekanan darah diastolik $>120 \mathrm{mmHg}$. Apabila ditemukan ada tanda-tanda kerusakan organ target maka penderita masuk kedalam kategori emergensi yang harus diberikan tatalaksana tindakan secara agresif untuk menurunkan tekanan darah dengan cepat. Berikut ini merupakan beberapa tanda dan gejala kerusakan target organ, yaitu perubahan status neurologis salah satunya adalah penurunan skala Glasgow Coma Scale. Kondisi 
yang tergolong dalam kerusakan target organ yang bersifat progresif di antaranya adalah perubahan status neurologis, hipertensif ensefalopati (kekurangan asupan oksigen di otak karena peningkatan tekanan darah), infark serebri (kerusakan otak), perdarahan intrakranial (perdarahan di dalam otak), Iskemi atau infark miokard (serangan jantung), ventrikel kiri akut, edema paru akut, diseksi aorta, Insufisensi renal, dan eklampsia.

Penanganan pada hipertensi emergensi yaitu asupan makanan yang rendah akan natrium klorida (garam) adalah modifikasi life style yang harus diakukan. Asupan garam maksimal 4 gram/hari (seharusnya 1,5 -3,8 gram/hari). Selain itu, penderita hipertensi emergensi disarankan untuk konsumsi asupan yang tinggi akan serat, rendah akan lemak dan kolesterol. Gaya hidup yang baik dapat menurunkan tekanan darah dan bermanfaat untuk menurunkan kemungkinan terkena penyakit kardiovaskuler. Pada penderita hipertensi stage 1 yang tidak ada faktor resiko kardiovaskuler lain, maka penderita tersebut harus melaksanakan pola hidup sehat setidaknya 4-6 bulan. Bila setelah 6 bulan tidak ada penurunan tekanan darah atau terdapat faktor resiko kardiovaskuler yang lain, maka diharapkan pasien tersebut memulai untuk konsumsi obat sebagai tindakan farmakologi.

Beberapa pola hidup sehat yang disarankan oleh beberapa guidelines antara lain menurunkan berat badan. Mengganti makanan-makanan cepat saji atau makanan yang tidak sehat dengan memperbanyak asupan buah dan sayur yang dapat menurunkan tekanan darah, dan menghindari diabetes melitus dan dislipidemia, serta meminimalkan asupan garam. Masyarakat beberapa daerah di Indonesia, makanan tinggi garam dan lemak merupakan kandungan yang banyak pada makanan tradisional. Tidak jarang pula, penderita hipertensi tidak menyadari kandungan garam yang tinggu pada makanan cepat saji, daging-daging olahan, makanan kaleng dll.

Olah raga. Olah raga yang teratur 30-60 menit dalam sehari, 3x dalam seminggu, dapat membantu menurunkan tekanan darah. Apabila tidak banyak waktu untuk berolah raga, maka dianjurkan untuk tetap berjalan kaki, menaiki tangga, atau mengendarai sepeda secara rutin sebagai alokasi dari olah raga. Meminimalkan konsumsi alkohol. Konsumsi alkohol lebih dari 2 gelas pada laki-laki, atau 1 gelas pada perempuan, dapat meningkatkan tekanan darah. Sehingga meminimalkan atau tidak konsumsi alkohol dapat membantu menurunkan tekanan darah. Merokok merupakan salah satu pemicu penyakit kardiovaskuler sehingga dianjurkan untuk tidak merokok.

Hipertensi emergensi merupakan penyakit yang harus diturunkan segera (dalam 1 jam) dengan target penurunan tekanan darah 20-25\% atau tekanan darah diastolik 110-115 mmHg. Bila target waktu 1 jam dapat dicapai dan pasien dalam kondisi stabil, penurunan tekanan darah selanjutnya dilakukan dalam $12-24$ jam. Penurunan tekanan darah yang telalu cepat dan drastis juga tidak baik, karena akan memperburuk aliran darah ke organ target. Obat anti hipertensi yang baik untuk hipertensi emergensi adalah obat parenteral yang bekerja cepat, mudah untuk dititrasi dan memberikan efek samping yang minimal. Obat yang digunakan adalah obat yang disesuaikan dengan kondisi pasien atau kondisi penyakit penyerta apabila 
ada organ target yang terkena. Secara general, terapi obat pada pasien hipertensi dimulai apabila pada pasien hipertensi stage 1 yang tidak mengalami penurunan tekanan darah lebih dari 6 bulan dengan menjalani pola hidup sehat.

\section{METODE}

Kegiatan pengabdian kepada masyarakat ini dilakukan dengan beberapa tahapan, antara lain :

a. Analisis situasi awal

Analisis situasi awal, dilaksanakan melalui metode survey. Kegiatan ini dilakukan pada 2 Januari 2020. Metode observasi dan wawancara digunakan dalam tahap ini. Teknis wawancara dalam tahap ini menanyakan terkait dengan kejadian hipertensi dan hipertensi emergensi, program untuk penanggulangan hipertensi dan tindakan apa yang telah dilakukan.

b. Pelaksanaan kegiatan

Kegiatan ini dilaksanaan pada tanggal 10 Januari 2020, dihadiri 29 lansia. Kegiatan ini dilakukan dalam bentuk pemberian pendidikan kesehatan melalui penyuluhan terkait dengan hipertensi emergensi dalam 1 kali waktu dengan media powerpoint dan pembagian leaflet.

c. Evaluasi

Evaluasi kegiatan dilakukan pada tanggal 14 Februari 2020 dengan metode pengisian kuesioner melalui wawancara kepada lansia terkait dengan hipertensi emergensi. Kuesioner yang dipakai dalam tahap ini meliputi beberapa pertanyaan terkait dengan definisi hipertensi emergensi, tanda gejala dan penanganan.

\section{HASIL}

Pelaksanaan pendidikan kesehatan diikuti oleh 29 lansia, kegiatan tersebut mendapatkan respon yang baik oleh mereka. Audience mengerti tentang hipertensi emergensi.

Tabel 1. Hasil Peningkatan Pengetahuan tentang Hipertensi Emergensi

\begin{tabular}{lccccc}
\hline \multirow{2}{*}{ Pertanyaan } & \multicolumn{2}{c}{$\begin{array}{c}\text { Sebelum } \\
\text { penyuluhan }\end{array}$} & \multicolumn{2}{c}{$\begin{array}{c}\text { Setelah } \\
\text { penyuluhan }\end{array}$} & \\
\cline { 2 - 5 } & Tahu & $\begin{array}{c}\text { Tidak } \\
\text { tahu }\end{array}$ & Tahu & $\begin{array}{c}\text { Tidak } \\
\text { tahu }\end{array}$ & \\
\cline { 2 - 5 } & 2 & 27 & 24 & 5 & $82,1 \%$ \\
Definisi & 12 & 17 & 27 & 2 & $52 \%$ \\
Tanda Gejala & 15 & 14 & 28 & 1 & $45 \%$ \\
Penanganan & 15 & &
\end{tabular}

Tabel 1 menyebutkan bahwa sebelum dilakukan kegiatan ini, 27 lansia tidak mengetahui tentang definisi, 17 lansia tidak mengetahui tentang tanda dan gejala, 14 lansia tidak mengetahui tentang penanganan. Setelah dilakukan kegiatan pengabdian masyarakat, 24 lansia mengetahui tentang definisi, 27 lansia mengetahui tentang tanda dan gejala, 28 lansia mengetahui tentang penanganan hipertensi emergensi. 


\section{PEMBAHASAN}

Hasil dari monitoring dan evaluasi yang dilakukan setelah pelaksanaan pengabdian masyarakat, didapatkan hal yang positif, yakni pemahaman tentang hipertensiemergensi. Menurut World Health Organisation (WHO), lansia merupakan seseorang dengan usia lebih dari 60 tahun. Lansia merupakan kelompok usia yang memasuki tahap akhir kehidupan yang melewati proses menua. Proses menjadi tua merupakan suatu proses yang dilewati manusia, pada proses ini terjadi kehilangan kemampuan jaringan secara perlahan untuk memperbaiki atau mengganti jaringan itu sendiri, penurunan kemampuan untuk mempertahankan fungsi normalnya, sehingga rentan terhadap infeksi dan memperbaiki kerusakan jaringan (Padila, 2013).

Usia yang paling rentan terhadap peningkatan tekanan darah adalah usia lanjut. Hal ini sejalan dengan data dari WHO yang menunjukkan prevalensi hipertensi meningkat sejalan dengan bertambahnya usia seseorang. Satu dari tiga orang dewasa di seluruh dunia mempunyai tekanan darah tinggi (WHO, 2013). Apapun tanda-tanda dan gelaja yang biasanya muncul pada penderita hipertensi adalah tekanan darah yang tinggi, pusing di area belakang kepala, gangguan keseimbangan dan kadang muncul mual (Smeltzer, Bare, Hinkle and Cheever, 2014). Tekanan darah yang tinggi dapat diatasi dengan farmakologi maupun non farmakologi. Penatalaksanaan dengan farmakologi merupakan pengobatan hipertensi dengan menggunakan terapi obat, sedangkan penatalaksanaan nonfarmakologi merupakan cara untuk menstabilkan tekanan darah yang dapat dilakukan dengan tindakan selain pemberian obat (Smeltzer, Bare, Hinkle and Cheever, 2014).

Pentingnya dilakukan penyuluhan tentang hipertensi emergensi salah satunya adalah untuk mencegah terjadinya kematian ketika serangan hipertensi emergensi. Dengan adanya peningkatan pengetahuan tentang kejadian tersebut dapat menurunkan resiko kematian pada lansia dengan serangan hipertensi emergensi, karena mereka mengerti apa yang seharusnya dilakukan. Pendidikan seseorang dapat meningkatkan kematangan pemikiranya sehingga dapat dan mampu mengambil keputusan terbaik dalam menjaga status kesehatanya. Pendidikan yang tinggi akan memungkinkan individu memiliki kemampuan memahami potensi dari suatu keadaan untuk menimbulkan penyakit sehinga lebih memperhatikan usaha-usaha menjaga kesehatan (Notoatmodjo, 2013). Media yang digunakan ketika memberikan pendidikan kesehatan merupakan salah satu keberhasilan dari tindakan yang dilakukan. Dengan menggunakan power point dan leaflet, informasi yang disampaikan melalui indera penglihatan lebih banyak.

\section{KESIMPULAN DAN SARAN}

\subsection{Kesimpulan}

Pendidikan Kesehatan kepada lansia di posyandu menur, Windan, Makamhaji, Kartasura dapat meningkatkan pengetahuan lansia tentang hipertensi emergensi.

\subsection{Saran}

Pendidikan kesehatan yang berkelanjutan, agar lansia mampu mengenali tanda dan gejalanya, sehingga dapat menanganinya dengan tepat. 


\section{UCAPAN TERIMA KASIH}

Ucapan terimakasih kepada LPPM Universitas Kusuma Husada Surakarta dan Posyandu Lansia Menur, Windan, Makamhaji, Kartasura yang telah mendukung kegiatan pengabdian kepada masyarakat ini sehingga kegiatan ini dapat dilaksanakan dengan baik.

\section{DAFTAR RUJUKAN}

AHA (American Heart Association). (2013). High Blood Pressure. Amerika: American Heart Association.

Dinas Kesehatan Jawa Tengah. (2016). https://dinkesjatengprov.go.id/v2018/

JNC-8. (2014). The Eight Report of the Joint National Committee. Hypertension Guidelines: An In-Depth Guide. Am J Manag Care

Kemenkes. (2014). Info Datin Pusat Data dan Informasi Kementrian Kesehatan RI. Kemenkes RI. 109 (1) : Jakarta.

Kowalski, Robert. (2010). Terapi Hipertensi: Program 8 minggu Menurunkan Tekanan Darah Tinggi. Alih Bahasa: Rani Ekawati. Bandung: Qanita Mizan Pustaka.

Martha, Karina. (2012). Panduan Cerdas Mengatasi Hipertensi, Yogyakarta: Araska Padila. (2013). Asuhan Keperawatan Penyakit Dalam. Yogyakarta: Nuha Medika

Riset Kesehatan Dasar. (2018)

S. Notoatmodjo. (2013). Promosi Kesehatan Global. Jakarta: Rineka Cipta.

Smetltzer SC, Bare BG, Hinkle JL and Cheever KH. (2014). Medical Surgical Nursing. Vol 1.12 ed. Lippincot William and Wilkins : Philadelphia

Survei Indikator Kesehatan Nasional. (2016)

Whelton PK, Carey RM, Aronow WS, Casery DE, Collins KJ, Himmelfarb CD, et al. (2017). ACC/AHA/AAPA/ABC/ACPM/AGS/ APhA/ ASH/ ASPC/ NMA / PCNA Guideline for the Prevention, Detection, Evaluation, and Management of High Blood Pressure in Adults. Hypertension 2018;71:e13-e115

World Health Organization. (2013). A global brief on hypertension: silent killer, global public health crisis. 